\title{
O papel da comunidade de fungos micorrízicos arbusculares (FMA) autóctones no desenvolvimento de espécies vegetais nativas em área de dunas de restinga revegetadas no litoral do Estado da Paraíba
}

\author{
JOÃO RICARDO GONÇALVES DE OLIVEIRA ${ }^{1}$, RENATA GOMES DE SOUZA', \\ FÁBIO SÉRGIO BARBOSA DA SILVA², ALESSANDRA SALVIANO MONTEIRO MENDES ${ }^{3}$ e \\ ADRIANA MAYUMI YANO-MELO ${ }^{4,5}$,
}

(recebido: 4 de setembro de 2008; aceito: 24 de junho de 2009)

\begin{abstract}
Role of autoctone community of arbuscular mycorrhizal fungi (AMF) on the development of native plant species in revegetated restinga dunes from coastal region of Paraíba State). Association of arbuscular mycorrhizal fungi (AMF) and plant roots constituted one of the most important ways to mitigate the impact of disturbed area. The aim of this work was to characterize the AMF community in the soil from revegetated dune area and to analyze its influence on the native plant development. Soils were collected in rainfall season in the revegetated area. Glomalin-related soil protein production (GRSP), glomerospores density and diversity were evaluated. The influence of AMF autoctone community was determined for two native plants: Tabebuia roseo-alba (Ridl.) Sandw. (peroba) and Tocoyena selloana Schum. (jenipapo-bravo). Experimental design for each species was completely randomized with 10 replicates, two treatment - native soil (SN) and disinfested native soil (SND) - were tested. Parameters evaluated were: height, shoot diameter, leaf number and area, shoot and root dry mass, nutrient contents, glomerospore density, mycorrhizal colonization and glomalin-related soil protein production (GRSP). In dune revegetated soil was found 1 glomerospore $\mathrm{g}^{-1}$ soil and $1.20 \pm 0.04 \mathrm{mg} \mathrm{GRSP} \mathrm{g}^{-1}$ soil, and six AMF species were identified. Native soil promoted more development to plant and fungi. Mycorrhizal colonization in peroba was $80 \%$ and in jenipapobravo $60 \%$. Then, AMF are present in revegetated area after mining contributing to growth of native plant species studied in greenhouse conditions, suggesting that their performance is affected by arbuscular mycorrhiza symbiosis.
\end{abstract}

Key words - arbuscular mycorrhiza, native plant species, restinga

RESUMO - (O papel da comunidade de fungos micorrízicos arbusculares (FMA) autóctones no desenvolvimento de espécies vegetais nativas em área de dunas de restinga revegetadas no litoral do Estado da Paraíba). A simbiose entre fungos micorrízicos arbusculares (FMA) com raízes de plantas vasculares constitui uma das mais importantes formas de mitigar o impacto das áreas pertubadas. O trabalho objetivou caracterizar a comunidade de FMA presente no solo de área de duna revegetada e avaliar sua influência sobre o desenvolvimento de espécies nativas. Foi realizada coleta de solo durante o período chuvoso em área revegetada, avaliando-se: produção de proteínas do solo relacionadas à glomalina (PSRG), densidade e diversidade de glomerosporos. A influência da comunidade nativa de FMA foi determinada para duas espécies vegetais nativas: Tabebuia roseoalba (Ridl.) Sandw. (peroba) e Tocoyena selloana Schum. (jenipapo-bravo). Para cada espécie foram testados dois tratamentos - solo nativo (SN) e solo nativo desinfestado (SND) - em delineamento inteiramente casualizado com 10 repetições. Ao final foram avaliados: altura, diâmetro do caule, número de folhas, área foliar, biomassa seca e conteúdo de nutrientes nas partes aérea e radicular, densidade de glomerosporos, colonização micorrízica hifálica, arbuscular, vesicular e total e produção de

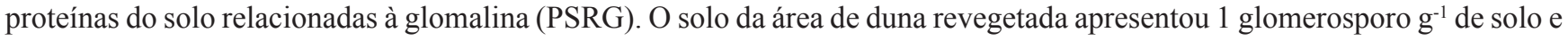
$1,20 \pm 0,04 \mathrm{mg} \mathrm{PSRG} \mathrm{g}^{-1}$ solo, sendo identificadas seis espécies de FMA. Maior desenvolvimento vegetal e fúngico ocorreram no SN. A colonização micorrízica na peroba foi de $80 \%$ e no jenipapo-bravo $60 \%$. Os FMA estão presentes em áreas revegetadas após extração de minérios, e contribuem para o crescimento das espécies nativas testadas em condições de casa de vegetação, sugerindo assim, que o desempenho dessas plantas é influenciado pela simbiose micorrízica arbuscular.

Palavras-chave - micorriza arbuscular, plantas nativas, restinga

1. Universidade Federal de Pernambuco, UFPE, Depto. Micologia, CCB, Programa de Pós-graduação em Biologia de Fungos, Rua Nelson Chaves, s/n., 50670-420 Recife, PE, Brasil.

2. Universidade de Pernambuco, UPE, Campus Petrolina, BR 203, $\mathrm{km}$ 2, 56300-000 Petrolina, PE, Brasil.

3. Embrapa Semi-Árido, Caixa Postal 23, 56304-970 Petrolina, PE, Brasil.

4. Universidade Federal do Vale do São Francisco, Univasf, Colegiado de Zootecnia, Av. José de Sá Maniçoba, s/n, Centro, 56304-917 Petrolina, PE, Brasil.

5._Autor para correspondência: amymelo17@hotmail.com.br

\section{Introdução}

A associação entre alguns fungos do solo e raízes da maioria dos vegetais, conhecida como micorriza, é uma relação mutualista benéfica, com perfeita interação morfo-fisiológica. As micorrizas podem ser classificadas de acordo com as características morfo-anatômicas da raiz colonizada em: ectomicorrizas, ectendomicorrizas e endomicorrizas. Dentre estas, a endomicorriza arbuscular, 
formada pelos fungos micorrízicos arbusculares (FMA), é provavelmente a simbiose predominante nos ecossistemas terrestres (Smith \& Read 1997).

A simbiose micorrízica arbuscular pode aumentar a superfície de absorção das raízes, melhorando a aquisição de íons de baixa mobilidade como P, Zn e $\mathrm{Cu}$ (Smith \& Read 1997), resultando no aumento da tolerância do vegetal a estresses abióticos e bióticos, como patógenos do solo (Maia et al. 2006), seca (Augé 2001) e salinidade (Maia \& Yano-Melo 2005). Além disso, os FMA contribuem para a melhoria na estruturação do solo (Rillig 2004), gerando benefícios para qualidade edáfica (Caravaca et al. 2005), podendo, ainda influenciar a diversidade vegetal (Bever 2003). É também essencial para a regeneração de áreas degradadas, atuando na melhoria da estruturação do solo, contribuindo para redução dos riscos de erosão e desertificação (Caravaca et al. 2005). No Brasil, os principais fatores de degradação do solo são o desmatamento e as atividades agrícolas (agricultura e pecuária), no entanto, o impacto causado por atividades de mineração também resulta em conseqüências prejudiciais ao ecossistema (Dias \& Griffith 1988).

A reabilitação de áreas degradadas é difícil e lenta, envolvendo o desenvolvimento de tecnologias apropriadas. A universalidade da associação micorrízica arbuscular (Bécard et al. 2004), aliada ao papel desempenhado pelas comunidades de microrganismos do solo quanto a melhoria das condições edáficas e crescimento de plantas (Bever 2003), podem constituir ferramenta biotecnológica na recuperação de ambientes degradados. Porém, para a efetiva utilização, o papel da simbiose em áreas em processo de reabilitação deve ser definido, de forma a contribuir para melhoria das características físicas e biológicas, bem como na redução dos custos de recuperação de sistemas impactados.

Desta forma, o presente trabalho objetivou avaliar a influência da comunidade de FMA presente no solo de área de dunas de restingas revegetadas do litoral da Paraíba sobre o desenvolvimento de duas espécies vegetais nativas.

\section{Material e métodos}

Área de estudo - Localizada no Município de Mataraca, extremo norte do Estado da Paraíba (6 $6^{\circ} 28^{\prime} 20^{\prime \prime}-6^{\circ} 30$ '00" S, $\left.34^{\circ} 55^{\prime} 50^{\prime \prime}-34^{\circ} 57^{\prime} 10^{\prime \prime} \mathrm{W}\right)$, a mineradora Millennium Inorganic Chemicals Mining extrai das dunas litorâneas os minerais titaníferos ilmenita, rutilo e zirconita, que são matérias-primas na indústria de pigmento, eletrodos de solda e cerâmicas, respectivamente. A vegetação típica é a de restinga que reveste as dunas costeiras, com tipos arbóreos, arbustivos e herbáceos que ocorrem sobre praias estreitas e sobre dunas fixas podendo atingir até $100 \mathrm{~m}$ de altitude (Oliveira-Filho \& Carvalho 1993). O clima da região é tropical e chuvoso, tipo Am de Köppen segundo Silva et al. (2000), com período de seca curto (principalmente dezembro) e precipitação média anual de $1.795 \mathrm{~mm}$. A formação geológica predominante é composta de rochas sedimentares argilo-arenosas, sobrepostas por dunas. O processo de extração dessa riqueza mineral produz rejeito, constituído basicamente por areia quartzosa, que é depositada nas áreas exploradas para posteriormente recompor as dunas. Após a reconstituição física, as dunas são revegetadas com mudas de plantas nativas: Anacardium occidentale L., Tapirira guianensis Aubl. (Anacardiaceae), Tabebuia roseo-alba (Ridl.) Sandw. (Bignoniaceae), Tocoyena selloana Schum., Guettarda platypoda DC. (Rubiaceae), Manilkara salzmanii (A. DC.) H. J. Lam. (Sapotaceae), Zizyphus joazeiro Mart. (Rhamnaceae), entre outras. Estudos para recuperação e estabilização das dunas de rejeito foram iniciados em 1987, com o suporte técnico da Universidade Federal de Lavras e desde então, tem sido constatado o avanço do processo da sucessão ecológica, com conseqüente complexação estrutural da vegetação e aumento da diversidade vegetal (Cunha et al. 2003).

Coleta e caracterização do solo - Foi realizada coleta de solo durante o período chuvoso (junho/2006), selecionada uma subárea que passou por processo de revegetação iniciado em 1989. Foram coletados cerca de $200 \mathrm{~kg}$ de solo rizosférico, com a seguinte caracterização química: $\mathrm{pH}=5,6$; C.E. $\left(\right.$ condutividade elétrica) $=1,12 \mathrm{dS} \mathrm{m}^{-1} ; \mathrm{P}$ (fósforo) $=$ $16 \mathrm{mg} \mathrm{dm}^{-3} ; \mathrm{K}$ (potássio) $=0,1 \mathrm{cmol}_{\mathrm{c}} \mathrm{dm}^{-3} ; \mathrm{Ca}$ (cálcio) $=$ $2 \mathrm{cmol}_{\mathrm{c}} \mathrm{dm}^{-3} ; \mathrm{Mg}$ (magnésio) $=0,9 \mathrm{cmol}_{\mathrm{c}} \mathrm{dm}^{-3} ; \mathrm{Na}$ (sódio) $=0,74 \mathrm{cmol}_{\mathrm{c}} \mathrm{dm}^{-3} ; \mathrm{Al}$ (alumínio) $=0,1 \mathrm{cmol}_{\mathrm{c}} \mathrm{dm}^{-3}$; CTC (capacidade de troca catiônica) $=8,19 \mathrm{cmol}_{\mathrm{c}} \mathrm{dm}^{-3} \mathrm{e} 15,2 \mathrm{~g} \mathrm{~kg}^{-1}$ de M.O. (matéria orgânica). As coletas foram feitas de forma aleatória, formadas por vinte amostras compostas, sendo cada uma constituída por três subamostras da região rizosférica das plantas predominates na área de coleta e descritas na área de estudo, até uma profundidade de $20 \mathrm{~cm}$. O solo foi acondicionado em sacos plásticos e posteriormente processado no Laboratório de Micorrizas (UFPE). Parte do solo coletado foi utilizado para avaliar a produção de proteínas do solo relacionadas à glomalina (PSRG), densidade e diversidade de glomerosporos. A porção restante foi utilizada em casa de vegetação para determinação da influência da comunidade nativa de FMA para duas espécies vegetais nativas.

Quantificação de glomerosporos - As amostras de solo foram homogeneizadas e peneiradas (malha de $5 \mathrm{~mm}$ ) antes de serem processadas. Para extração dos glomerosporos foram utilizados $50 \mathrm{~g}$ do solo (5 repetições) empregando-se as técnicas de decantação e peneiramento úmido (Gerdemann \& Nicolson 1963), seguidas por centrifugação em água e sacarose $\left(40 \% \mathrm{p} \mathrm{v}^{-1}\right)$ (Jenkins 1964), e a contagem realizada 
em placas canaletadas, sob estereomicroscópio (40x). Para melhor caracterizar a comunidade de FMA do solo testado, foram identificadas seis espécies: Acaulospora longula Spain \& Schenck, Acaulospora scrobiculata Trappe, Acaulospora foveata Trappe \& Janos, Glomus aggregatum Schenck \& Smith emend Koske, Glomus glomerulatum Sieverding e Glomus taiwanensis Wu \& Chen.

Quantificação das proteínas do solo relacionadas à glomalina (PSRG) - As PSRG foram extraídas do solo seguindo-se a metodologia de Wright \& Upadhyaya (1996): $2 \mathrm{~mL}$ de citrato de sódio (20 mM; pH 7,0) foram adicionados a $0,25 \mathrm{~g}$ de solo, seguindo-se a extração em autoclave $\left(121^{\circ} \mathrm{C}, 30 \mathrm{~min}\right)$. Após extração, o material foi centrifugado (10.000 g $5 \mathrm{~min}^{-1}$ ) e as PSRG presentes no sobrenadante foram quantificadas pelo método de Bradford (1976), tendo como curva-padrão a albumina soro bovina (BSA).

Experimento em casa de vegetação - Foram realizados experimentos com duas plantas nativas: peroba (Tabebuia roseo-alba (Ridl.) Sandw.) e jenipapo-bravo (Tocoyena selloana Schum.). Para cada experimento foram testados dois tratamentos - solo desinfestado (SD) e não desinfestado (SND) - com dez repetições, em delineamento inteiramente casualizado. Parte do solo coletado foi fumigado por $48 \mathrm{~h}$ com Bromex $^{\circledR}$ (98\% brometo de metila e $\%$ cloropicrina). Sementes de peroba e de jenipapo-bravo, coletadas e fornecidas pela empresa Lyondell-Millennium, foram colocadas em bandejas contendo vermiculita e após as plântulas apresentarem no mínimo três folhas definitivas, foram transplantadas para sacos pretos contendo $2 \mathrm{~kg}$ dos respectivos tratamentos de solo. Após 120 dias foram avaliados: altura, diâmetro do caule, número de folhas (quinzenalmente), área foliar, biomassa seca e conteúdo de nutrientes aéreo e radicular, PSRG, densidade de glomerosporos, colonização micorrízica hifálica, arbuscular, vesicular e total (McGonigle et al. 1990). Para análise da área foliar, as imagens foram capturas por câmara digital e posteriormente analisadas pelo programa SIARCS 3.0 (Embrapa-CNPDIA 1996) e a biomassa seca vegetal por gravimetria após secagem em estufa $\left(60^{\circ} \mathrm{C}\right)$ até peso constante. Para determinação do incremento produzido pela presença do FMA foi utilizada a fórmula de Edginton et al. $(1971)$ adaptada: $\mathrm{I}(\%)=\left[(\mathrm{Tr}-\mathrm{T}) \mathrm{T}^{-1}\right] \times 100$, onde; I $(\%)=$ incremento da variável; $\operatorname{Tr}=$ valor médio para o tratamento com solo nativo; $\mathrm{T}=$ valor médio do controle com solo nativo desinfestado. Para conteúdo de nutrientes foliar e radicular, da matéria seca triturada em moinho do tipo Willye, porções de $0,5 \mathrm{~g}$ da amostra foram mineralizadas por digestão nitro-perclórica e determinados os teores de $\mathrm{Ca}, \mathrm{Mg}$, $\mathrm{Fe}, \mathrm{Zn}, \mathrm{Cu}$ e Mn, por espectrofotometria de absorção atômica; P por colorimetria e K, por fotometria de emissão de chama. Todas as análises foram realizadas conforme metodologia da Embrapa (1999) e os valores obtidos foram multiplicados pela biomassa seca. A densidade de glomerosporos foi determinada como descrito anteriormente. A colonização micorrízica foi estimada pelo método de McGonigle et al. (1990), após diafanização das raízes com $\mathrm{KOH} 10 \%$ e $\mathrm{H}_{2} \mathrm{O}_{2}$ $10 \%$, acidificação em $\mathrm{HCl} 1 \%$ e posterior coloração com azul de Trypan (0,05\%) (Phillips \& Hayman 1970).

Análises estatísticas - Para satisfazer a homogeneidade de variância, os dados de densidade de glomerosporos foram transformados em $\log (\mathrm{x}+1)$ e os de colonização micorrízica total, hifálica, arbuscular e vesicular em arco seno $(\sqrt{\mathrm{x} / 100})$. Os dados foram submetidos à análise de variância e as médias foram comparadas pelo teste de Tukey, utilizando-se o programa Statistica 5.0 (Statsoft 1997).

\section{Resultados e discussão}

Número de glomerosporos em solo de dunas - A densidade de glomerosporos foi de 1 glomerosporo $\mathrm{g}^{-1}$ de solo, número considerado baixo quando comparado ao observado por Trufem (1995), a qual registrou média de 1,93 glomerosporos $\mathrm{g}^{-1}$ de solo em ecossistema de restinga na Ilha do Cardoso, SP. Porém, os valores são comparativamente similares aos obtidos por Silva et al. (2001), que recuperaram menos de 1,6 g $\mathrm{g}^{-1}$ solo, em áreas impactadas por atividade mineradora, na região semi-árida da Bahia.

Adicionalmente, o número de glomerosporos variou de 0,9 a 8,06 esporos $\mathrm{g}^{-1}$ de solo em áreas salinizadas e de caatinga, respectivamente (Yano-Melo et al. 2003a, Souza et al. 2003), estando o presente resultado dentro da faixa observada por estes autores. Outros fatores como pluviosidade, temperatura, período de insolação e, sobretudo o hospedeiro influenciam a esporulação de FMA (Maia \& Trufem 1990), podendo resultar em variação na densidade de glomerosporos no campo como observado por Caproni et al. (2003).

Gould et al. (1996) relataram que maior tempo pode ser necessário para recuperação de elevadas quantidades de glomerosporos, em áreas em processo de sucessão vegetal, pois a energia do micobionte pode estar destinada à colonização radicular e conseqüente estabelecimento dos vegetais nessas áreas. Dessa forma, a avaliação da colonização radicular por FMA na área de estudo poderia contribuir para compreensão dos resultados obtidos em relação à densidade de glomerosporos. No entanto, Caproni et al. (2003) registraram em áreas revegetadas que ocorria diminuição da densidade de glomerosporos de acordo com a sucessão temporal, atribuindo este fato a estabilização do sistema estudado, como observado na floresta primária. Assim, estudos prolongados associando a freqüência de espécies de FMA ao longo do tempo poderiam confirmar se essa hipótese se confirma na área estudada. 
Quantificação de PSRG em solo de dunas - A glomalina é uma glicoproteína produzida pelos FMA que contribui para a melhoria na estruturação do solo (Rillig 2004), gerando benefícios para a qualidade edáfica (Caravaca et al. 2005). No presente estudo, a produção de PSRG foi comparativamente maior $\left(1,20 \pm 0,04 \mathrm{mg}\right.$ PSRG g${ }^{-1}$ solo) do que o obtido por Bird et al. (2002) no semi-árido do Novo México, os quais extraíram 0,3-0,6 mg PSRG g-1 de solo. Em outros ecossistemas, como fragmentos de Mata Atlântica (Melo 2004), extraiu-se 22 mg PSRG g-1 de solo, fato possivelmente relacionados aos teores de matéria orgânica nessas áreas, uma vez que Rosier et al. (2006) observaram que a matéria orgânica pode superestimar os valores de PSRG do solo.

Segundo Rillig et al. (2001), os fatores que estão envolvidos no controle da produção de PSRG no ambiente ainda não são claros, porém concentrações de nutrientes, clima e possivelmente a diversidade de FMA, bem como hospedeiro e sua produtividade, podem influenciar a deposição e dessas proteínas no solo.

Experimentos em casa de vegetação - Maior crescimento vegetal foi observado quando as plantas foram cultivadas em solo nativo não desinfestado, em comparação ao tratamento de solo desinfestado. Isto sugere que a microbiota do solo desempenha importante papel no desenvolvimento de mudas em solos de áreas revegetadas.

Com exceção do número de folhas, diferenças no crescimento das mudas de jenipapo-bravo em função dos tratamentos do solo, foram obtidas 30 dias após o transplantio. Nas mudas de peroba, o efeito dos tratamentos foi mais tardio, visto que diferenças significativas quanto ao crescimento vegetal foram constatadas somente após 75 dias do transplantio (tabela 1).

Tabela 1. Médias de altura, número de folhas e diâmetro do caule de peroba - Tabebuia roseo-alba e jenipapo-bravo - Tocoyena selloana, aos 15, 30, 45, 60, 75, 90, 105 e 120 dias pós-transplante para solo nativo (SN) e nativo desinfestado (SND).

Table 1. Average height, leaf number and shoot diameter of peroba - Tabebuia roseo-alba and jenipapo-bravo - Tocoyena selloana plants, at 15, 30, 45, 60, 75, 90, 105 and 120 days after transplantation to native (SN) and disinfected native (SND) soils.

\begin{tabular}{|c|c|c|c|c|c|c|c|c|c|}
\hline & \multirow{2}{*}{$\begin{array}{l}\text { Tratamentos } \\
\text { por espécie }\end{array}$} & \multicolumn{8}{|c|}{ Tempo (dias) } \\
\hline & & 15 & 30 & 45 & 60 & 75 & 90 & 105 & 120 \\
\hline \multirow{6}{*}{ 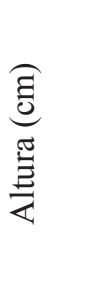 } & Peroba & & & & & & & & \\
\hline & $\mathrm{SN}$ & $3,25 \mathrm{a}$ & $3,65 \mathrm{a}$ & $4,14 \mathrm{a}$ & $5,05 \mathrm{a}$ & $6,20 \mathrm{a}$ & $7,20 \mathrm{a}$ & $8,25 \mathrm{a}$ & $10,00 \mathrm{a}$ \\
\hline & SND & $3,33 \mathrm{a}$ & $3,74 \mathrm{a}$ & $4,26 \mathrm{a}$ & $4,77 \mathrm{a}$ & $5,40 \mathrm{~b}$ & $5,50 \mathrm{~b}$ & $5,40 \mathrm{~b}$ & $5,80 \mathrm{~b}$ \\
\hline & Jenipapo-bravo & & & & & & & & \\
\hline & $\mathrm{SN}$ & $3,75 \mathrm{a}$ & $4,32 \mathrm{a}$ & $5,70 \mathrm{a}$ & $7,50 \mathrm{a}$ & $9,50 \mathrm{a}$ & $13,50 \mathrm{a}$ & $14,90 \mathrm{a}$ & $17,20 \mathrm{a}$ \\
\hline & SND & $3,35 \mathrm{a}$ & $3,60 \mathrm{~b}$ & $4,05 \mathrm{~b}$ & $4,05 \mathrm{~b}$ & $4,30 \mathrm{~b}$ & $4,60 \mathrm{~b}$ & $4,76 \mathrm{~b}$ & $4,85 \mathrm{~b}$ \\
\hline \multirow{6}{*}{ 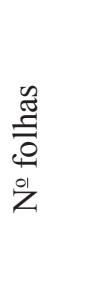 } & Peroba & & & & & & & & \\
\hline & SN & $4,50 \mathrm{a}$ & $5,50 \mathrm{a}$ & $7,40 \mathrm{a}$ & $8,80 \mathrm{a}$ & $10,40 \mathrm{a}$ & $12,50 \mathrm{a}$ & $13,60 \mathrm{a}$ & $18,80 \mathrm{a}$ \\
\hline & SND & $5,00 \mathrm{a}$ & $6,33 \mathrm{a}$ & $8,00 \mathrm{a}$ & $8,55 \mathrm{a}$ & $9,30 \mathrm{~b}$ & $9,30 \mathrm{~b}$ & $9,50 \mathrm{~b}$ & $9,70 \mathrm{~b}$ \\
\hline & Jenipapo-bravo & & & & & & & & \\
\hline & $\mathrm{SN}$ & $4,00 \mathrm{a}$ & $4,00 \mathrm{a}$ & $6,40 \mathrm{a}$ & $8,20 \mathrm{a}$ & $10,00 \mathrm{a}$ & $11,80 \mathrm{a}$ & $12,80 \mathrm{a}$ & $12,80 \mathrm{a}$ \\
\hline & SND & $4,00 \mathrm{a}$ & $4,00 \mathrm{a}$ & $4,00 \mathrm{~b}$ & $4,60 \mathrm{~b}$ & $5,20 \mathrm{~b}$ & $5,80 \mathrm{~b}$ & $6,40 \mathrm{~b}$ & $6,40 \mathrm{~b}$ \\
\hline \multirow{6}{*}{ 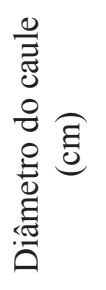 } & Peroba & & & & & & & & \\
\hline & $\mathrm{SN}$ & $0,15 \mathrm{a}$ & $0,17 \mathrm{~b}$ & $0,24 \mathrm{a}$ & $0,30 \mathrm{~b}$ & $0,33 \mathrm{a}$ & $0,40 \mathrm{a}$ & $0,44 \mathrm{a}$ & $0,57 \mathrm{a}$ \\
\hline & SND & $0,15 \mathrm{a}$ & $0,19 \mathrm{a}$ & $0,26 \mathrm{a}$ & $0,32 \mathrm{a}$ & $0,35 \mathrm{a}$ & $0,37 \mathrm{~b}$ & $0,41 \mathrm{a}$ & $0,42 \mathrm{~b}$ \\
\hline & Jenipapo-bravo & & & & & & & & \\
\hline & $\mathrm{SN}$ & $0,20 \mathrm{a}$ & $0,22 \mathrm{a}$ & $0,25 \mathrm{a}$ & $0,30 \mathrm{a}$ & $0,32 \mathrm{a}$ & $0,38 \mathrm{a}$ & $0,46 \mathrm{a}$ & $0,44 \mathrm{a}$ \\
\hline & SND & $0,18 \mathrm{a}$ & $0,19 \mathrm{~b}$ & $0,22 \mathrm{~b}$ & $0,22 \mathrm{~b}$ & $0,22 \mathrm{~b}$ & $0,23 \mathrm{~b}$ & $0,23 \mathrm{~b}$ & $0,25 \mathrm{~b}$ \\
\hline
\end{tabular}

Médias seguidas pela mesma letra na coluna (para cada espécie vegetal) não diferem entre si pelo teste de Tukey $(P<0,05)$. Means for each species followed by the same letter in the column did not show any significant difference from each other by Tukey test $(P<0.05)$. 
Em solo nativo não desinfestado, as mudas de peroba tiveram incrementos de 79,64\%, 75,93\% e $76,79 \%$ para área foliar, biomassa seca aérea e radicular, respectivamente, quando comparadas com as do solo nativo desinfestado. De forma mais acentuada, obteve-se incrementos de $88,36 \%, 88,34 \%$ e $87,17 \%$ para área foliar, biomassa seca aérea e radicular das mudas de jenipapo-bravo, respectivamente, em relação ao solo nativo desinfestado (tabela 2).

Ao final dos experimentos, observou-se que maior número de glomerosporos foi registrado no solo nativo

Tabela 2. Médias da área foliar (AF) e biomassa seca aérea (BSA) e subterrânea (BSS) da peroba - Tabebuia roseo-alba e do jenipapo-bravo - Tocoyena selloana, em solo nativo (SN) e nativo desinfestado (SND), 120 dias pós-transplante.

Table 2. Average leaf area (AF) and shoots dry weight (BSA) and roots dry weight (BSS) of Tabebuia roseo-alba and Tocoyena selloana plants in native soil (SN) and disinfested native soil (SND) at 120 days after transplantation.

\begin{tabular}{lcccc}
\hline Espécie vegetal & Solo & $\begin{array}{c}\text { AF } \\
\left(\mathrm{cm}^{2}\right)\end{array}$ & $\begin{array}{c}\text { BSA } \\
(\mathrm{g})\end{array}$ & $\begin{array}{c}\text { BSS } \\
(\mathrm{g})\end{array}$ \\
\hline Peroba & SN & $295,27 \mathrm{a}$ & $1,73 \mathrm{a}$ & $1,46 \mathrm{a}$ \\
& SND & $60,10 \mathrm{~b}$ & $0,41 \mathrm{~b}$ & $0,34 \mathrm{~b}$ \\
Jenipapo-bravo & SN & $362,37 \mathrm{a}$ & $2,15 \mathrm{a}$ & $1,40 \mathrm{a}$ \\
& SND & $42,17 \mathrm{~b}$ & $0,25 \mathrm{~b}$ & $0,18 \mathrm{~b}$ \\
\hline
\end{tabular}

Médias seguidas pela mesma letra na coluna, dentro de cada espécie vegetal, não diferem entre si pelo teste de Tukey $(P<0,05)$. Means within the same species followed by the same letter in the column did not show any significant difference from each other by Tukey test $(P<0.05)$. não desinfestado, em relação ao tratamento com solo desinfetado, recuperando-se menos de um glomerosporo $\mathrm{g}^{-1}$ solo, para ambas as espécies vegetais (peroba e jenipapo-bravo).

Devido ao fato da fumigação eliminar propágulos de FMA, foi registrada elevada colonização micorrízica das raízes de peroba e jenipapo-bravo cultivados em solo não desinfestado (tabela 3). Os arbúsculos, responsáveis pela participação na transferência de nutrientes, e conseqüente funcionalidade da simbiose (Barker et al. 1998) podem ter contribuído para maximizar o crescimento vegetal. Carneiro et al. (1998) registraram colonização micorrízica média (49-20\%) para a peroba (Tabebuia roseo-alba) em condições de viveiro e casa de vegetação respectivamente. Já para uma outra espécie do gênero Tocoyena [Tocoyena formosa (Cham. \& Schltdl) K. Schum.] foram observados níveis baixos (19-1\%) de colonização quando coletadas no cerrado. Os valores obtidos no presente estudo são comparativamente superiores (tabela 3), exceto com relação à Tabebuia roseo-alba, onde Zangaro et al. (2002), também em condições de casa de vegetação, observaram colonização elevada (80\%), contudo tais resultados são representativos do sucesso no estabelecimento da simbiose.

A produção de proteínas do solo relacionada à glomalina não diferiu entre os tratamentos de solo, após cultivo do jenipapo-bravo (tabela 3). É provável que a duração do experimento não tenha sido suficiente para se detectar deposição diferenciada de glomalina, como sugerido por Silva (2006). Embora fosse esperado que o solo nativo (SN) cultivado apresentasse maior PSRG do que o solo nativo desinfestado (SND), tal fato não ocorreu nos vasos cultivados com peroba,

Tabela 3. Percentual de colonização radicular total (CT), hifálica $(\mathrm{CH})$, arbuscular (CA), vesicular (CV) e produção de proteínas do solo relacionadas à glomalina (PSRG) em mudas de jenipapo-bravo (Tocoyena selloana) e peroba (Tabebuia roseo-alba) cultivadas em solo nativo (SN) e nativo desinfestado (SND), 120 dias pós-transplante.

Table 3. Percentage of total root (CT), hifal (CH), arbuscular (CA), and vesicular (CV) colonization and production of glomalinrelated soil protein (PSRG) in Tocoyena selloana and Tabebuia roseo-alba plants, cultivated in native soil (SN) and disinfected native soil (SND), 120 days after transplantation.

\begin{tabular}{llrrrrr}
\hline \multirow{2}{*}{ Plantas } & Solo & \multicolumn{1}{c}{ CT } & CH & CA & CV & \multirow{2}{*}{$\begin{array}{c}\text { PSRG } \\
\text { (mg g }\end{array}$} \\
\cline { 3 - 6 } Peroba) & SN & $79,14 \mathrm{a}$ & $61,79 \mathrm{a}$ & $1,88 \mathrm{a}$ & $15,48 \mathrm{a}$ & $1,32 \mathrm{~b}$ \\
& SND & $3,61 \mathrm{~b}$ & $2,74 \mathrm{~b}$ & $0,00 \mathrm{~b}$ & $0,87 \mathrm{~b}$ & $1,81 \mathrm{a}$ \\
\multirow{2}{*}{ Jenipapo-bravo } & SN & $60,79 \mathrm{a}$ & $54,88 \mathrm{a}$ & $1,11 \mathrm{a}$ & $4,80 \mathrm{a}$ & $1,57 \mathrm{a}$ \\
& SND & $2,62 \mathrm{~b}$ & $1,98 \mathrm{~b}$ & $0,00 \mathrm{~b}$ & $0,63 \mathrm{~b}$ & $1,14 \mathrm{a}$ \\
\hline
\end{tabular}

Médias seguidas pela mesma letra na coluna, dentro de cada espécie vegetal, não diferem entre si pelo teste de Tukey $(P<0,05)$. Means followed by the same letter in column, between for each species, did not differ from each other by Tukey test $(P<0.05)$. 
reforçando a constatação de Treseder \& Turner (2007) que demonstraram que nem sempre há correlação entre produção de PSRG, densidade de hifa e colonização por FMA, além da possível influência do hospedeiro vegetal sobre essa produção. Outro fato que pode ocorrer é que a porção glicídica das PSRG pode servir como fonte de energia para microbiota edáfica, como sugerido por outras pesquisas (Harner et al. 2005). Tal comportamento sugere que as PSRG além de contribuírem para a agregação e estabilidade do solo, desempenham importante papel para microbiota edáfica nas áreas revegetadas, participando da ciclagem do carbono.

Em relação ao conteúdo nutricional, observa-se que em peroba houve efeito dos tratamentos de fumigação (tabela 4), pois plantas mantidas em solo nativo apresentavam maior teor $\mathrm{P}, \mathrm{Mg}, \mathrm{Cu}, \mathrm{Zn}$ e $\mathrm{Na}$ na raiz do que as cultivadas em solo nativo desinfestado, enquanto nas folhas, somente o $\mathrm{Cu}$ era encontrado em maior quantidade. Maior absorção de $\mathrm{P}, \mathrm{Cu}$ e $\mathrm{Zn}$ em plantas micorrizadas tem sido referida (Pouyu-Rojas et al. 2006), enquanto $\mathrm{Na}$ ocorre o inverso, ou seja, plantas micorrizadas apresentam menor teor desse nutriente, como forma de mitigar os efeitos prejudiciais do excesso de sal (Maia \& Yano-Melo 2005), sugerindo efeito protetor da microbiota associada.

Em jenipapo-bravo, observou-se maior teor de $\mathrm{P}$, $\mathrm{Ca}$ e $\mathrm{Mg}$ na parte aérea em plantas micorrizadas em relação às não micorrizadas. Similarmente, na parte radicular, os teores de $\mathrm{P}, \mathrm{K}, \mathrm{Ca}, \mathrm{Mg}, \mathrm{S}, \mathrm{Fe}, \mathrm{Mn}, \mathrm{Zn}$ e $\mathrm{Na}$ foram superiores nas plantas micorrizadas, diferindo estatisticamente das plantas não micorrizadas (tabela 4). Nesse caso, não houve redução no acúmulo de Na pelas plantas micorrizadas, fato que poderá estar relacionado ao micobionte associado, considerando que Yano-Melo et al. (2003b) observaram que as espécies de FMA podem diferir quanto à absorção de $\mathrm{Na}$.

$\mathrm{O}$ aumento nos teores de nutrientes proporcionado pela microbiota associada às plantas de peroba e jenipapobravo variou, sugerindo que a colonização micorrízica nas raízes dessas plantas tenha sido realizada por FMA distintos, já que associações preferenciais podem ser observadas na simbiose micorrízica (Sanders 2003), além de grau diferenciado de compatibilidade fungohospedeiro (Pouyu-Rojas et al. 2006). Tal fato torna ainda mais relevante o conhecimento do papel dos FMA na estruturação das comunidades e no funcionamento

Tabela 4. Conteúdo médio dos macronutrientes ( $\mathrm{P}, \mathrm{K}, \mathrm{Ca}, \mathrm{Mg}$ e S em g planta $\left.{ }^{-1}\right)$ e micronutrientes $(\mathrm{Cu}, \mathrm{Fe}, \mathrm{Mn}$ e $\mathrm{Zn}$ em mg planta $\left.^{-1}\right)$ e $\mathrm{Na}\left(\mathrm{mg} \mathrm{planta}^{-1}\right)$ na parte aérea e radicular de mudas de peroba e jenipapo-bravo cultivadas em solo desinfestado (SND) e não desinfestado (SN), 120 dias pós-transplante.

Table 4. Average macronutrient ( $\mathrm{P}, \mathrm{K}, \mathrm{Ca}, \mathrm{Mg}$ and $\mathrm{S}$ in $\mathrm{g}$ by plant), micronutrient ( $\mathrm{Cu}, \mathrm{Fe}, \mathrm{Mn}$ and $\mathrm{Zn}$ in $\mathrm{mg}$ by plant), and $\mathrm{Na}$ (mg by plant) contents in shoots and roots of peroba and jenipapo-bravo plants, cultivated in native (SN) and disinfected native (SND) soils, 120 days after transplantation.

\begin{tabular}{|c|c|c|c|c|c|c|c|c|c|c|}
\hline & $\mathrm{P}$ & $\mathrm{K}$ & $\mathrm{Ca}$ & $\mathrm{Mg}$ & $\mathrm{S}$ & $\mathrm{Cu}$ & $\mathrm{Fe}$ & $\mathrm{Mn}$ & $\mathrm{Zn}$ & $\mathrm{Na}$ \\
\hline & \multicolumn{5}{|c|}{ g planta ${ }^{-1}$} & \multicolumn{5}{|c|}{ mg planta ${ }^{-1}$} \\
\hline \multicolumn{11}{|c|}{ Peroba - parte aérea } \\
\hline SN & $1,0 \mathrm{a}$ & $10,2 \mathrm{~b}$ & $12,6 \mathrm{a}$ & $4,9 \mathrm{a}$ & $2,5 \mathrm{a}$ & $11,4 \mathrm{a}$ & $25,4 \mathrm{a}$ & $193,8 \mathrm{a}$ & $53,8 \mathrm{a}$ & $11900,0 \mathrm{~b}$ \\
\hline SND & $0,9 \mathrm{a}$ & $11,4 \mathrm{a}$ & $12,7 \mathrm{a}$ & $5,2 \mathrm{a}$ & $2,2 \mathrm{a}$ & $8,2 \mathrm{~b}$ & $168,8 \mathrm{a}$ & $188,0 \mathrm{a}$ & $49,5 \mathrm{a}$ & $15111,1 \mathrm{a}$ \\
\hline \multicolumn{11}{|c|}{ Jenipapo-bravo - parte aérea } \\
\hline SN & $1,03 \mathrm{a}$ & $8,3 \mathrm{a}$ & $6,16 \mathrm{a}$ & $4,18 \mathrm{a}$ & $1,5 \mathrm{a}$ & $53,0 \mathrm{a}$ & $525,4 \mathrm{a}$ & $162,0 \mathrm{a}$ & $71,2 \mathrm{a}$ & 7760,0 a \\
\hline SND & $0,38 \mathrm{~b}$ & $7,4 \mathrm{a}$ & $2,93 \mathrm{~b}$ & $2,56 \mathrm{~b}$ & $1,2 \mathrm{a}$ & $56,2 \mathrm{a}$ & $454,0 \mathrm{a}$ & $173,7 \mathrm{a}$ & $73,1 \mathrm{a}$ & 6611,1 a \\
\hline \multicolumn{11}{|c|}{ Peroba - parte radicular } \\
\hline $\mathrm{SN}$ & $0,93 \mathrm{a}$ & $8,0 \mathrm{a}$ & $2,9 \mathrm{a}$ & $2,41 \mathrm{a}$ & $1,4 \mathrm{a}$ & $36,8 \mathrm{a}$ & $1557,8 \mathrm{a}$ & 365,8 a & $100,8 \mathrm{a}$ & 8444,4 a \\
\hline SND & $0,35 \mathrm{~b}$ & $6,7 \mathrm{a}$ & $2,9 \mathrm{a}$ & $1,62 \mathrm{~b}$ & $1,2 \mathrm{a}$ & $10,0 \mathrm{~b}$ & 1193,3 a & $213,1 \mathrm{a}$ & $29,1 \mathrm{~b}$ & $11050,0 \mathrm{~b}$ \\
\hline \multicolumn{11}{|c|}{ Jenipapo-bravo - parte radicular } \\
\hline SN & $1,07 \mathrm{a}$ & $8,85 \mathrm{a}$ & $1,96 \mathrm{a}$ & $2,73 \mathrm{a}$ & $1,26 \mathrm{a}$ & $63,8 \mathrm{a}$ & $1091,6 \mathrm{a}$ & $107,6 \mathrm{a}$ & $100,2 \mathrm{a}$ & $6930,0 \mathrm{a}$ \\
\hline SND & $0,33 \mathrm{~b}$ & $5,16 \mathrm{~b}$ & $1,08 \mathrm{~b}$ & $1,93 \mathrm{~b}$ & $0,86 \mathrm{~b}$ & $62,5 \mathrm{a}$ & $184,6 \mathrm{~b}$ & $35,8 \mathrm{~b}$ & $40,5 \mathrm{~b}$ & $473,3 \mathrm{~b}$ \\
\hline
\end{tabular}

Médias seguidas pela mesma letra na coluna, dentro de cada espécie vegetal, não diferem entre si pelo teste de Tukey $(P<0,05)$. Means followed by the same letter in column, between for each species, did not differ from each other by Tukey test $(P<0.05)$. 
dos ecossistemas, principalmente na reabilitação de áreas tropicais, onde predominam solos de baixa fertilidade e as micorrizas são potenciais essenciais para o sucesso da revegetação.

Agradecimentos - Ao CNPq, pela concessão da bolsa de IC (J.R.G. Oliveira) e PP (A.M. Yano-Melo), à Empresa Lyondell-Millennium Inorganic Chemicals do Brasil S.A., à Embrapa Semi-Árido e a todos do Laboratório de Micorrizas da Universidade Federal de Pernambuco.

\section{Referências bibliográficas}

AUGÉ, R.M. 2001. Water relations, drought and vesiculararbuscular mycorrhizal symbiosis. Mycorrhiza 11:3-24.

BARKER, S.J., TAGU, D. \& DELP, G. 1998. Regulation of root and fungal morphogenesis in mycorrhizal symbioses. Plant Physiology 116:1201-1207.

BEVER, J.D. 2003. Soil community feedback and the coexistence of competitors: conceptual frameworks and empirical tests. New Phytologist 157:465-473.

BÉCARD, G., KOSUTA, S., TAMASLOUKHT, M., SÉJALON-DELMAS, N. \& ROUX, C. 2004. Partner communication in the arbuscular mycorrhizal interaction. Canadian Journal of Botany 82:1186-1197.

BIRD, S.B., HERRICK, J.E., WANDER, M.M. \& WRIGTH, S.F. 2002. Spatial heterogeneity of aggregate stability and soil carbon in semi-arid rangeland. Environmental Pollution 116:445-455.

BRADFORD, M.M. 1976. A rapid and sensitive method for the quantification of microgram quantities of protein utilizing the principle of protein-dye binding. Analytical Biochemistry 72:248-254.

CAPRONI, A.L., FRANCO, A.A., BERBARA, R.L.L., TRUFEM, S.B., GRANHA, J.R.D.O. \& MONTEIRO, A.B. 2003. Ocorrência de Fungos Micorrízicos Arbusculares em áreas revegetadas após mineração de bauxita em Porto Trombetas, Pará. Pesquisa Agropecuária Brasileira 38:1409-1418.

CARAVACA, F., ALGUACIL, M.M., BAREA, J.M. \& ROLDÁN, A. 2005. Survival of inocula and native AM fungi species associated with shrubs in a degraded Mediterranean ecosystem. Soil Biology and Biochemistry 37:227-233.

CARNEIRO, M.A.C., SIQUEIRA, J.O., MOREIRE, F.M.S., CARVALHO, D., BOTELHO, S.A. \& JUNIOR, O.J. 1998. Micorriza arbuscular em espécies arbóreas e arbustivas nativas de ocorrência no sudeste do Brasil. Cerne 4:129-145.

CUNHA, L.O., FONTES, M.A.L., OLIVEIRA, A.D. \& OLIVEIRA-FILHO, A.T. 2003. Análise multivariada da vegetação como ferramenta para avaliar a reabilitação de dunas litorâneas mineradas em Mataraca, Paraíba, Brasil. Revista Árvore. 27:503-515.
DIAS, L.E. \& GRIFFTH, J.J. 1988. Conceituação e caracterização de áreas degradadas. In Recuperação de áreas degradadas (L.E. Dias \& J.W.V. Mello, eds.). Sociedade Brasileira de Recuperação de Áreas Degradadas, Departamento de Solos, Viçosa UFV, p.252.

EDGINTON, L.V., KHEW, K.L. \& BARRON, G.L. 1971. Fungitoxic spectrum of benzimidazole compounds. Phytopathology 61:42-44.

EMBRAPA 1999. Manual de análises químicas de solos, plantas e fertilizantes. Embrapa Solos/Embrapa Informática Agropecuária/Embrapa Comunicação para Transferência de Tecnologia, Brasília.

EMBRAPA-CNPDIA. 1996. SIARCS 3.0 (Sistema Integrado para Analise de Raízes e Cobertura do Solo). Embrapa, Brasília.

GERDEMANN, J.W. \& NICOLSON, T.H. 1963. Spores of mycorrhizal Endogone species extracted from soil by wet sieving and decanting. Transactions of the British Mycological Society. 46:235-244.

GOULD, A.B, HENDRIX, J.W. \& FERRISS, R.S. 1996. Relationship of mycorrhizal activity to time following reclamation of surface mine land in western Kentucky - I: propagule and spore population densities. Canadian Journal of Botany 74:247-261.

HARNER, M.J., RAMSEY, P.W. \& RILLIG, M.C. 2005. Protein accumulation and distribution in foodplain and river foam. Ecology Letters 7:829-836.

JENKINS, W.R. 1964. A rapid centrifugal-flotation technique for separating nematodes from soil. Plant Disease Report 48:692.

MAIA, L.C. \& TRUFEM, S.F.B. 1990. Fungos Micorrízicos Vesículo-Arbusculares em solos cultivados no Estado de Pernambuco, Brasil. Revista Brasileira de Botânica 13:89-95.

MAIA, L.C. \& YANO-MELO, A.M. 2005. Role of arbuscular mycorrhizal fungi in saline soils. In Mycorrhizas: role and applications (V.S. Mehrotra, ed.). Allied Publishers, New Dehli, p.282-302.

MAIA, L.C., SILVEIRA, N.S.S. \& CAVALCANTE, U.M.T. 2006. Interaction between arbuscular mycorrhizal fungi and root pathogens. In Handbook of microbial biofertilizers (M.K. Rai, org.). The Haworth Press Inc, New York, p.325-352.

MCGONIGLE, T.P., MILLER, M.H., EVANS, D.G., FAIRCHILD, G.L. \& SWAN, J.A. 1990. A new method which gives an objective measure of colonization of roots by vesicular-arbuscular mycorrhizal fungi. New Phytologist 115:495-501.

MELO, A.M.M. 2004. Fungos micorrízicos arbusculares (Glomeromycota) em fragmentos de Mata Atlântica no centro de endemismo Pernambuco. Dissertação de mestrado, Universidade Federal de Pernambuco, Recife. 
OLIVEIRA-FILHO, A.T. \& CARVALHO, D.A. 1993. Florística e fisionomia da vegetação no extremo norte do litoral da Paraíba. Revista Brasileira de Botânica 16:115-130.

PHILLIPS, J.M. \& HAYMAN, D.S. 1970. Improved procedures for clearing roots and staining parasitic and vesicular arbuscular mycorrhizal fungi for rapid assessment of infection. Transactions of British Mycological Society 55:158-161.

POUYU-ROJAS, E., SIQUEIRA, J.O. \& SANTOS, J.G.D. 2006. Compatibilidade simbiótica de fungos micorrízicos arbusculares com espécies arbóreas tropicais. Revista Brasileira de Ciências do Solo 30:413-424.

RILLIG, M.C. 2004. Arbuscular mycorrhizae, glomalin, and soil aggregation. Canadian Journal of Soil Science 84:355-363.

RILLIG, M.C., WRIGHT, S.F., NICHOLS, K.A., SCHMIDT, W.F. \& TORN, M.S. 2001. Large contribution of arbuscular mycorrhizal fungi to soil carbon pools in tropical forest soils. Plant and Soil 233:167-177.

ROSIER, C.L., HOYE, A.T. \& RILLIG, M. 2006. Glomalin related soil protein: assessment of current detection and quantification tools. Soil Biology Biochemistry 38:2205-2211.

SANDERS, I.R. 2003. Preference, specificity and cheating in the arbuscular mycorrhyzal symbiosis. Trends in Plant Science 8:143-145.

SANTOS, M., ROSADO, S.C.S., OLIVEIRA-FILHO, A.T. \& CARVALHO, D. 2000. Correlações entre variáveis do solo e espécies herbáceo-arbustivas de dunas em revegetação no Litoral norte da Paraíba. Cerne 6:19-29.

SILVA, F.S.B.2006. Fase assimbiótica, produção, infectividade e efetividade de fungos micorrízicos arbusculares (FMA) em substratos com adubos orgânicos. Tese de doutorado, Universidade Federal de Pernambuco, Recife.
SILVA, G.A., MAIA, L.C., SILVA, F.S.B. \& LIMA, P.C.F. 2001. Potencial de infectividade de fungos micorrízicos arbusculares oriundos de área de caatinga nativa e degradada por mineração, no Estado da Bahia, Brasil. Revista Brasileira de Botânica 24:135-143.

SMITH, S.E. \& READ, D.J. 1997. Mycorrhizal symbiosis. Academic Press, San Diego.

SOUZA, R.G., MAIA, L.C., SALES, M.F. \& TRUFEM, S.F.B. 2003. Diversidade e potencial de infectividade de fungos micorrízicos arbusculares em área de caatinga, na região de Xingó, Estado de Alagoas, Brasil. Revista Brasileira de Botânica 26:49-60.

STATSOFT INC. 1997. Statistica for windows. Tulsa, USA.

TRESEDER, K.K. \& TURNER, K.M. 2007. Glomalin in ecosystems. Soil Science Society American Journal 71:1257-1266.

TRUFEM, S.F.B. 1995. Aspectos ecológicos de fungos micorrízicos arbusculares na rizosfera de plantas de restinga da Ilha do Cardoso, SP, Brasil. Revista Brasileira de Botânica 18:51-60.

WRIGHT, S.F. \& UPADHYAYA, A. 1996. Extraction of an arbuscular and unusual protein from soil and comparision on hyphal protein of arbuscular mycorrhizal fungi. Soil Science 161:575-586.

YANO-MELO, A.M., TRUFEM, S.F.B. \& MAIA, L.C. 2003a. Arbuscular mycorrhizal fungi in salinized and surrounded áreas at the São Francisco Submedium Valley, Brazil. Hoehnea 30:79-87.

YANO-MELO, A.M., SAGGIN JÚNIOR, O.J. \& MAIA, L.C. 2003b. Tolerance of mycorrhized banana (Musa sp. cv. Pacovan) plantlets to saline stress. Agriculture Ecosystems Environment 95:343-348.

ZANGARO, W., NISIZAKI, S.M.A., DOMINGOS, J.C.B. \& NAKANO, E.M. 2002. Micorriza arbuscular em espécies arbóreas nativas da bacia do rio Tibagi, Paraná. Cerne 8:77-87. 